\title{
Heterologous Production of $\beta$-Caryophyllene and Evaluation of Its Activity against Plant Pathogenic Fungi
}

\author{
Fabienne Hilgers ${ }^{1,+} \oplus^{\oplus}$, Samer S. Habash ${ }^{2,+}{ }^{\oplus}$, Anita Loeschcke ${ }^{1}$, Yannic Sebastian Ackermann ${ }^{1}{ }^{(}$, \\ Stefan Neumann $^{2}$, Achim Heck ${ }^{3}{ }^{\mathbb{D}}$, Oliver Klaus $\left.{ }^{1}{ }^{(}\right)$, Jennifer Hage-Hülsmann ${ }^{1}$, Florian M. W. Grundler ${ }^{2}{ }^{\mathbb{D}}$, \\ Karl-Erich Jaeger ${ }^{1,3} \mathbb{C}^{-}$, A. Sylvia S. Schleker ${ }^{2, * \mathbb{C}}$ and Thomas Drepper ${ }^{1, * \mathbb{C}}$
}

1 Institute of Molecular Enzyme Technology, Heinrich-Heine-University Düsseldorf, Forschungszentrum Jülich, Wilhelm-Johnen-Straße, 52428 Jülich, Germany; f.hilgers@fz-juelich.de (F.H.); a.loeschcke@fz-juelich.de (A.L.); y.ackermann@fz-juelich.de (Y.S.A.); o.klaus@fz-juelich.de (O.K.); j.hage-huelsmann@fz-juelich.de (J.H.-H.); karl-erich.jaeger@fz-juelich.de (K.-E.J.)

2 INRES-Molecular Phytomedicine, University of Bonn, Karlrobert-Kreiten-Str. 13, 53115 Bonn, Germany; samer@uni-bonn.de (S.S.H.); sneuman1@uni-bonn.de (S.N.); grundler@uni-bonn.de (F.M.W.G.)

3 Institute of Bio- and Geosciences (IBG-1: Biotechnology) Forschungszentrum Jülich, Wilhelm-Johnen-Straße, 52428 Jülich, Germany; a.heck@fz-juelich.de

* Correspondence: sylvia.schleker@uni-bonn.de (A.S.S.S.); t.drepper@fz-juelich.de (T.D.)

+ These authors contributed equally to this work.

Citation: Hilgers, F.; Habash, S.S.; Loeschcke, A.; Ackermann, Y.S.; Neumann, S.; Heck, A.; Klaus, O.; Hage-Hülsmann, J.; Grundler, F.M.W.; Jaeger, K.-E.; et al. Heterologous Production of $\beta$-Caryophyllene and Evaluation of Its Activity against Plant Pathogenic Fungi. Microorganisms 2021, 9, 168. https://doi.org/10.3390/ microorganisms 9010168

Received: 10 December 2020 Accepted: 10 January 2021 Published: 14 January 2021

Publisher's Note: MDPI stays neutral with regard to jurisdictional clai$\mathrm{ms}$ in published maps and institutional affiliations.

Copyright: $\odot 2021$ by the authors. Licensee MDPI, Basel, Switzerland. This article is an open access article distributed under the terms and conditions of the Creative Commons Attribution (CC BY) license (https:// creativecommons.org/licenses/by/ $4.0 /)$.

\begin{abstract}
Terpenoids constitute one of the largest and most diverse groups within the class of secondary metabolites, comprising over 80,000 compounds. They not only exhibit important functions in plant physiology but also have commercial potential in the biotechnological, pharmaceutical, and agricultural sectors due to their promising properties, including various bioactivities against pathogens, inflammations, and cancer. In this work, we therefore aimed to implement the plant sesquiterpenoid pathway leading to $\beta$-caryophyllene in the heterologous host Rhodobacter capsulatus and achieved a maximum production of $139 \pm 31 \mathrm{mg} \mathrm{L}^{-1}$ culture. As this sesquiterpene offers various beneficial anti-phytopathogenic activities, we evaluated the bioactivity of $\beta$-caryophyllene and its oxygenated derivative $\beta$-caryophyllene oxide against different phytopathogenic fungi. Here, both compounds significantly inhibited the growth of Sclerotinia sclerotiorum and Fusarium oxysporum by up to $40 \%$, while growth of Alternaria brassicicola was only slightly affected, and Phoma lingam and Rhizoctonia solani were unaffected. At the same time, the compounds showed a promising low inhibitory profile for a variety of plant growth-promoting bacteria at suitable compound concentrations. Our observations thus give a first indication that $\beta$-caryophyllene and $\beta$-caryophyllene oxide are promising natural agents, which might be applicable for the management of certain plant pathogenic fungi in agricultural crop production.
\end{abstract}

Keywords: terpenoids; sesquiterpene production; Rhodobacter capsulatus; $\beta$-caryophyllene; bioactivity; phytopathogens; plant pathogenic fungi; plant growth-promoting bacteria

\section{Introduction}

Among secondary metabolites, terpenoids including the class of sesquiterpenoids represent one of the largest and most diverse groups with over 80,000 known compounds, mostly isolated from plants [1-4]. Based on their number of carbon atoms, they can be divided into the subclasses of hemi- $\left(C_{5}\right)$, mono- $\left(C_{10}\right)$, sesqui- $\left(C_{15}\right)$, di- $\left(C_{20}\right)$, tri- $\left(C_{30}\right)$, tetra- $\left(C_{40}\right)$ and polyterpenes $\left(>C_{40}\right)[5,6]$. In general, the terpenoid synthesis starts from the two isoprene intermediates isopentenyl pyrophosphate (IPP) and dimethylallyl pyrophosphate (DMAPP), which are provided either by the mevalonate (MVA) pathway or by the 1-deoxy-D-xylulose 5-phosphate (DXP) pathway, also known as the 2-C-methyl-D-erythritol 4-phosphate (MEP) pathway. While the MVA pathway uses acetyl-Coenzyme A (acetyl$\mathrm{CoA}$ ) as a substrate and is predominantly found in eukaryotes (e.g., mammals, plants, 
and fungi), archaea and a few bacteria [7], the DXP pathway starts from glyceraldehyde-3phosphate (GAP) and pyruvate and primarily occurs in bacteria, cyanobacteria, and green algae [8]. Starting from IPP and DMAPP, the elongation of linear prenyl pyrophosphates is catalyzed by prenyltransferases via head-to-tail condensations and results in $C_{10}$ geranyl pyrophosphate (GPP), $\mathrm{C}_{15}$ farnesyl pyrophosphate (FPP), and $\mathrm{C}_{20}$ geranylgeranyl pyrophosphate (GGPP). Finally, GPP is used as a precursor molecule for the synthesis of monoterpenoids, FPP for sesqui- and triterpenoid production, and GGPP for di- and tetraterpenoid biosynthesis. Terpenes exhibit manifold functions in plant physiology and development, including photoprotection (carotenoids), communication (e.g., pinene), or repellant activity against predators and parasites (e.g., verbenone, $\beta$-caryophyllene) [9-11]. Furthermore, terpenes are of commercial interest for the pharmaceutical sector due to their various bioactivities suitable for the treatment of pathogen infections, inflammation, or cancer [12,13]. For example, the sesquiterpene farnesol shows inhibitory effects against antibiotic-resistant Staphylococci, not only inhibiting the growth of planktonic cells in free suspension but also suppressing biofilm formation of Staphylococcus aureus, Staphylococcus epidermidis, and Burkholderia pseudomallei [14-17]. In the past, these compounds were exclusively obtained from essential oils of natural plant sources, requiring complex and timeconsuming downstream processing. $\beta$-caryophyllene, for example, was extracted from Cannabis sativa [18], clove basil, Ocimum gratissimum [19], or representatives of the plant genus Cordia, such as Cordia verbenaceae [20]. However, the application of microorganisms as heterologous hosts allows the establishment of alternative, cost-effective, and sustainable biotechnological production processes [21-26]. As the efficiency of such processes strongly depends on the achieved production titers, metabolic engineering of the applied hosts together with the optimization of the respective secondary metabolite pathways has gained more attention in the recent past [1,27-31]. So far, terpenoids were mostly produced in the heterologous hosts Escherichia coli and Saccharomyces cerevisiae [32-36]. However, in recent studies, the terpene production in less common microbes such as phototrophs has also been established and optimized, as for example documented by the Rhodobacter-based production of $\beta$-farnesene, nootkatone, valencene, and amorphadiene [23,37-40], or the production of various terpenes in cyanobacteria [41].

The phototrophic non-sulfur $\alpha$-proteobacteria of the genus Rhodobacter feature some unique physiological properties, making them interesting microbial hosts for heterologous terpene production: (i) the cell membrane is commonly considered to be a critical determinant in terpenoid production since it can function as a storage compartment for the involved enzymes and metabolites [42,43]. In this context, Rhodobacter seems to be particularly suited for terpene production since the bacterium can form an extended intracytoplasmic membrane system (ICM), thereby providing a naturally enlarged reservoir for membrane-bound enzymes and terpenes [44,45]. (ii) As these phototrophic bacteria produce the carotenoids spheroidene and spheroidenone using the DXP pathway [46,47], they further offer a robust and effective isoprenoid metabolism that can be engineered for efficient terpenoid production. (iii) Rhodobacter species enable photo(hetero)tropic growth in low-cost minimal media at relatively high growth rates, allowing the utilization of sunlight as an energy source for sustainable cultivation and production processes. Recent studies could demonstrate that engineering the isoprenoid precursor biosynthesis can lead to a strong increase of sesqui- and triterpenoid formation in $R$. capsulatus $[39,48,49]$ and $R$. sphaeroides [38,40,50-52]. In particular, the co-expression of a terpene synthase with the FPP synthase IspA, and/or enzymes constituting the heterologous MVA pathway, resulted in enhanced production of the corresponding plant terpenoids.

A major problem in agricultural crop production is the large number of plant-damaging animals such as insects, mites, and nematodes or pathogens including viruses, bacteria, and fungi, some of which lead to high economic losses of around $60 \%$ globally [53]. One of the most widely distributed and destructive pathogens of plants causing white mold disease in more than 400 host plants all over the world is the fungus Sclerotinia sclerotiorum (Lib.) de Bary [54]. Another devastating example of fungal diseases is the plant vascular wilt 
caused by the Fusarium species [55]. Other fungal pathogens such as Phoma lingam [56,57], Alternaria brassicicola [58], and Rhizoctonia solani [59,60] also cause major yield reduction in important crops. To control these pathogens and due to the rapidly growing world population and the resulting increase of food consumption, farmers are using synthetic and biological substances as fertilizers, pesticides, or growth regulators side by side with the cultivation of resistant or tolerant plant varieties [61-64]. Each of these methods has its limitations, but so far, the use of pesticides is the most convenient and commonly used method. Nevertheless, these can have numerous severe side effects on the environment, including the soil [65]. The soil is inhabited by an enormous diversity of organisms that are important players in maintaining a functional ecosystem and that comprise microorganisms with beneficial properties for plant development and health. For that reason, effective and sustainable alternatives are needed. Firstly, plants, as a part of a complex ecosystem, can produce enormous amounts of secondary metabolites for their survival and maintenance. Phenolics and terpenes are examples of metabolites that are produced by plants and act as antimicrobial agents and feeding deterrents [66-72]. The presence of a wide range of terpenes encouraged their use as nature-inspired plant protection agents in agriculture or their use for drug development. One of the commonly stress-associated terpenes is the sesquiterpene $\beta$-caryophyllene [73-75]. As mentioned in the previous section, various studies showed that $\beta$-caryophyllene exhibits diverse biological activities against many organisms. From a plant protection perspective $\beta$-caryophyllene was reported to promote plant growth, to induce plant defense genes, to attract entomopathogenic nematodes, and to be active against certain plant pathogenic bacteria and fungi [76-80].

In this study, we therefore aimed to use the modular co-expression of DXP/MVA genes in combination with the strictly controlled $\mathrm{P}_{\text {nif }}$ promoter to reconstitute the pathway of the plant sesquiterpene $\beta$-caryophyllene in $R$. capsulatus and to optimize the production under phototrophic growth conditions. For heterologous sesquiterpene production, the $\beta$ caryophyllene synthase QHS1 from Artemisia annua was used. Since this terpene offers a variety of beneficial bioactivities, we further evaluated the potential use of $\beta$-caryophyllene and its oxygenated derivative $\beta$-caryophyllene oxide as nature-derived fungicides. To this end, the bioactivity of $\beta$-caryophyllene/oxide against both representative plant growthpromoting bacteria and phytopathogenic fungi was investigated.

\section{Materials and Methods}

\subsection{Bacterial Strains and Cultivation Conditions}

The Escherichia coli strain DH5 $\alpha$ and strain S17-1 were used for cloning and conjugation of plasmid DNA [81,82]. E. coli cells were cultivated at $37^{\circ} \mathrm{C}$ using LB agar plates or liquid medium (Luria/Miller, Carl Roth ${ }^{\circledR}$, Karlsruhe, Germany), containing kanamycin $\left(25 \mu \mathrm{g} \mathrm{mL}^{-1}\right)$ when appropriate. R. capsulatus SB1003 [83] and SB1003-MVA [39], encompassing the chromosomally located genes $m v a A$, idi, hsc, mvk, pmk and mvd (also designated as MVA gene cluster) from Paracoccus zeaxanthinifaciens, were used for plant terpene production. All R. capsulatus strains used in this study were either cultivated on PY agar plates [84] containing $2 \%(w / v)$ Select Agar (Thermo Fisher Scientific, Waltham, MA, USA) or in RCV liquid medium [85] at $30^{\circ} \mathrm{C}$. Both media were supplemented with rifampicin $\left(25 \mu \mathrm{g} \mathrm{mL}^{-1}\right)$. For cultivation of the recombinant Rhodobacter strain SB1003-MVA, gentamicin $\left(4 \mu \mathrm{g} \mathrm{mL}^{-1}\right)$ was further added to the medium. If not stated otherwise, photoheterotrophic cultivation was conducted under anaerobic conditions and permanent illumination with bulb light (2500 lx), as described previously [39]. All bacterial strains and plasmids used in this study are listed in Table S1 (Supplementary Materials). All strains for bioactivity and minimum inhibitory concentration (MIC) evaluation are listed in the respective results section.

\subsection{Construction of Expression Vectors}

The expression vectors used in this study are based on the pRhon5Hi-2 vector carrying the promoter of the nifH gene for heterologous gene expression [39]. The sequence of $\beta$-caryophyllene synthase QHS1 from A. annua (UniProt: Q8SA63) was used to generate 
an appropriate synthetic gene whose DNA sequence is suitable for the codon-usage of $R$. capsulatus. For DNA sequence adaptation, the Codon Optimization Tool by IDT Integrated DNA Technologies and the Graphical Codon Usage Analyzer tool were used [86]. The 1.7-kb QHS1 gene was obtained from Eurofins Genomics. The synthetic DNA fragment was flanked by appropriate restriction endonuclease recognition sequences (XbaI/HindIII). The final sequence of the synthetic DNA fragment is shown in the Supplementary Materials. For the construction, the XbaI/HindIII hydrolyzed QHS1 fragment was inserted into likewise hydrolyzed pRhon5Hi-2 as well as a variant, providing the additional isoprenoid biosynthetic gene ispA. Thereby, the expression vectors pRhon5Hi-2-QHS1 and pRhon5Hi-2-QHS1-ispA were constructed, carrying the terpene synthase gene immediately downstream of the $\mathrm{P}_{\text {nif }}$ promoter of the vector. Correct nucleotide sequences of all constructs were confirmed by Sanger sequencing (Eurofins Genomics, Ebersberg, Germany). The QHS1 expression vectors are summarized in Table S1 (Supplementary Materials).

\subsection{Cultivation of R. capsulatus for Heterologous Terpene Production}

For the expression of the heterologous terpene biosynthetic genes, respective pRhon5Hi2-based plasmids were transferred to cells of different $R$. capsulatus strains via conjugational transfer employing E. coli S17-1 as donor [84]. Thereafter, transconjugants were selected and further cultivated on PY agar containing kanamycin $\left(25 \mu \mathrm{g} \mathrm{mL}^{-1}\right)$ and rifampicin $\left(25 \mu \mathrm{g} \mathrm{mL}^{-1}\right)$. Subsequently, Rhodobacter cells were cultivated in airtight $4.5 \mathrm{~mL} \mathrm{screw}$ neck vials (Macherey-Nagel, Düren, Germany) or airtight $15 \mathrm{~mL}$ hungate tubes [87] in liquid RCV medium containing kanamycin $\left(25 \mu \mathrm{g} \mathrm{mL}^{-1}\right)$ and rifampicin $\left(25 \mu \mathrm{g} \mathrm{mL}^{-1}\right)$. Precultures were cultivated in $15 \mathrm{~mL} \mathrm{RCV}$ medium containing $0.1 \%\left(\mathrm{NH}_{4}\right)_{2} \mathrm{SO}_{4}$ inoculated with cells from a freshly grown PY agar plate and incubated for $48 \mathrm{~h}$ at $30{ }^{\circ} \mathrm{C}$ and with bulb light illumination. Expression cultures were inoculated from precultures to an optical density at $660 \mathrm{~nm}$ of 0.05 in $4.5 \mathrm{~mL}$ or $15 \mathrm{~mL} \mathrm{RCV}$ medium containing $0.1 \%$ serine as an exclusive nitrogen source. Subsequently, cells were incubated at $30^{\circ} \mathrm{C}$ under permanent illumination with bulb light $\left(3.6 \mathrm{~mW} \mathrm{~cm}^{-2}\right.$ at $\left.850 \mathrm{~nm}\right)$ or IR light $\left(5.6 \mathrm{~mW} \mathrm{~cm}^{-2}\right.$ at $\left.850 \mathrm{~nm}\right)$ for 3-5 days. For microaerobic expression cultures, cells were cultivated in $20-60 \mathrm{~mL}$ RCV medium containing $0.1 \%$ serine in $100 \mathrm{~mL}$ flasks at $30{ }^{\circ} \mathrm{C}$ and $130 \mathrm{rpm}$ in the dark. The absence of ammonium and the cultivation under oxygen-limited conditions led to the induction of the $\mathrm{P}_{n i f}$-dependent target gene expression. For the extraction of the produced sesquiterpenes, the cultures were overlaid with $150 \mu \mathrm{L}$ or $500 \mu \mathrm{L} n$-dodecane, respectively, during inoculation [88].

\subsection{Extraction, GC Analysis and Quantification of Sesquiterpenes}

Basically, analysis of produced sesquiterpenes was conducted as described in Troost et al., 2019 [39]. In the following, the procedure is briefly described. To facilitate terpene extraction into the organic phase (n-dodecane) after cultivation, screw neck vials or hungate tubes were incubated in a horizontal position under permanent shaking (130 rpm, $30{ }^{\circ} \mathrm{C}, 24 \mathrm{~h}$, in the dark) using a Multitron Standard incubation shaker (Infors HT). The $n^{-}$ dodecane samples were analyzed by gas chromatography (GC) using the Agilent 6890N gas chromatograph equipped with a (5\%-phenyl)-methylpolysiloxane HP-5 column (length, $30 \mathrm{~m}$; inside diameter, $0.32 \mathrm{~mm}$; film thickness, $0.25 \mu \mathrm{m}$; Agilent Technologies) and a flame ionization detector (FID). The temperatures of the injector and FID were set to 240 and $300{ }^{\circ} \mathrm{C}$, respectively. The GC was loaded with a 4 - $\mu \mathrm{L}$ sample of each $n$-dodecane layer using a split ratio of 100:1 with helium as carrier gas. The following column temperatures were used during analysis: (i) $100^{\circ} \mathrm{C}$ for $5 \mathrm{~min}$, (ii) increased of temperature with a heating rate of $10{ }^{\circ} \mathrm{C}$ per min up to $180{ }^{\circ} \mathrm{C}$, (iii) increased of temperature with a heating rate of $20^{\circ} \mathrm{C}$ per min up to $300^{\circ} \mathrm{C}$. The signal of $\beta$-caryophyllene produced in $R$. capsulatus was verified by comparison of its retention times to a corresponding reference ( $\beta$-caryophyllene from Sigma Aldrich, product number: 22075, retention time: $10.13 \mathrm{~min})$. In order to determine the final product titers, the transfer efficiency from producing cells into the $n$-dodecane phase was determined as described in Supplementary Method section "Analysis of $n$-dodecane- 
mediated $\beta$-caryophyllene extraction from phototrophically grown $R$. capsulatus". In brief, accumulated terpenes were extracted from cell lysates using $n$-dodecane. Subsequently, products were quantified using calibration curves of the reference compound, taking into account the specific transfer efficiencies of $\beta$-caryophyllene.

\subsection{Effect of $\beta$-Caryophyllene and $\beta$-Caryophyllene Oxide on Plant Pathogenic Fungi}

Isolates of the plant pathogenic fungi P. lingam, S. sclerotiorum and A. brassicicola were obtained from the Leibniz-Institut DSMZ (Deutsche Sammlung von Mikroorganismen und Zellkulturen GmbH, Braunschweig, Germany), while isolates of F. oxysporum, R. solani were obtained from the INRES, Plant Diseases and Plant Protection, University of Bonn. All isolates were sub-cultured on potato dextrose agar (PDA) at $24{ }^{\circ} \mathrm{C}$ and were used in this study to evaluate the bioactivity of the compounds on hyphal growth.

To test the bioactivities of $\beta$-caryophyllene and $\beta$-caryophyllene oxide, compounds were dissolved in a mixture of DMSO and Tween 20 (ratio of 1:2) to prepare differently concentrated stock solutions. These were mixed with PDA to gain the final concentrations $62.5,125$, and $250 \mu \mathrm{g} \mathrm{mL}^{-1}$ and to prepare PDA agar plates with terpenoids. The final DMSO and Tween 20 concentrations were always 1\% $(v / v)$ and $0.5 \%(v / v)$, respectively. Fungal discs with a diameter of $0.5 \mathrm{~cm}$ were cut from the culture media of freshly grown agar plates without terpenoids and placed upside down in the middle of PDA plates containing the chemicals. PDA plates with $0.5 \%(v / v)$ DMSO and $1 \%(v / v)$ Tween 20 alone were used as control. All plates were incubated for 7 days at $24^{\circ} \mathrm{C}$. Subsequently, the diameter of the fungal colony was measured, and the percentage of growth inhibition compared to the solvent control was calculated. Differences between the treatments were statistically analyzed using SigmaPlot software by one-way analysis of variance (ANOVA) and multiple comparisons for significance were performed at $(p<0.05)$ using the HolmSidak method.

\subsection{Determination of the Minimum Inhibitory Concentration (MIC) of $\beta$-Caryophyllene and $\beta$-Caryophyllene Oxide in Liquid Cultures of Bacteria}

The minimum inhibitory concentration of $\beta$-caryophyllene and $\beta$-caryophyllene was determined according to reference [89]. For the precultures, $10 \mathrm{~mL}$ Müller Hinton (MH) medium (Merck, Germany) was first inoculated in $100 \mathrm{~mL}$ flasks with four single bacterial colonies. For $R$. capsulatus, RCV was used. The liquid cultures were incubated for $18 \mathrm{~h}$ at $130 \mathrm{rpm}$ and $37^{\circ} \mathrm{C}$ (R. capsulatus at $30^{\circ} \mathrm{C}$ ). For the main cultures, $\mathrm{MH}$ or RCV medium was supplemented with differently concentrated stock solutions of $\beta$-caryophyllene and $\beta$-caryophyllene oxide in a mixture of DMSO and Tween 20 (ratio 1:2) to gain final concentrations of $62.5,125$, and $250 \mu \mathrm{g} \mathrm{mL}^{-1}$. All bacterial cultures were adjusted to a cell density corresponding to an optical density at $625 \mathrm{~nm}$ of 0.1 and then diluted 50-fold with medium for B. subtilis, P. putida, P. fluorescens, R. rhizogenes and P. polymyxa and 2-fold for R. capsulatus. For the inoculation of 96-well microtiter plates (Greiner Bio-One GmbH, Frickenhausen, Germany), $50 \mu \mathrm{L}$ MH medium with the corresponding concentration of the substance to be tested and the solvent controls were mixed with $50 \mu \mathrm{L}$ of previously diluted bacterial culture, resulting in an end optical density at $625 \mathrm{~nm}$ of 0.001 and 0.025 , respectively. The solvent control contained 1\% $(v / v)$ Tween 20 and $0.5 \%(v / v)$ DMSO. After inoculation, the microtiter plates (MTPs) were first shaken in a SpectraMax i3x (Molecular Devices, San Jose, CA, USA) plate photometer for $20 \mathrm{~s}$ to mix the solution and then incubated for $20 \mathrm{~h}$ at $37^{\circ} \mathrm{C}$. R. capsulatus was incubated at $30^{\circ} \mathrm{C}$ and $300 \mathrm{rpm}$. For subsequent determination of the MICs, the optical density of cell cultures was determined at $625 \mathrm{~nm}$ in a plate photometer. The MIC was defined based on the European Committee on Antimicrobial Susceptibility Testing (EUCAST) guidelines as the compound concentration at which an optical density at $625 \mathrm{~nm}$ minus the background absorbance equals 0 [90].

\section{Results}

In the past, terpenoids were exclusively obtained from natural plant sources, e.g., by extracting them from essential oils, requiring a complex and time-consuming downstream 
processing. The heterologous production of sesquiterpenes in a suitable microbial host, however, bears many benefits. For example, it offers the possibility to solely produce a desired compound so that it can be rather easily purified without the need of removing closely related constituents [21,34]. Thus, we here aimed to reconstitute the plant sesquiterpene pathway of $\beta$-caryophyllene in $R$. capsulatus and optimize the production under phototrophic growth conditions. Since many sesquiterpenoids exhibit promising antimicrobial activities, the antifungal efficacy of $\beta$-caryophyllene and its oxidized form against phytopathogenic fungi were evaluated.

\subsection{Establishment of $\beta$-Caryophyllene Production in R. capsulatus via Overexpression of Isoprenoid Precursor Genes}

Recently, we described the heterologous synthesis of the plant sesquiterpenoids valencene and patchoulol in the phototrophic bacterium $R$. capsulatus and its modular improvement by engineering the biosynthesis of the central precursor FPP [39]. To evaluate if $R$. capsulatus and the modular engineering principle can analogously be applied for the synthesis of the plant-derived sesquiterpene $\beta$-caryophyllene, we expressed the gene encoding $\beta$-caryophyllene synthase QHS1 from $A$. annua in the bacterial host. To this end, the expression vectors pRhon5Hi-2-QHS1 and pRhon5Hi-2-QHS1-ispA, carrying an additional copy of the intrinsic FPP synthase gene isp A, were transferred to the $R$. capsulatus wild type strain SB1003 and strain SB1003-MVA. The latter strain additionally contains the chromosomally integrated MVA pathway genes derived from Paracoccus zeaxanthinifaciens and thus offers a second isoprenoid biosynthesis pathway. To compare the $\beta$-caryophyllene production in all Rhodobacter strains grown under phototrophic conditions, cells were incubated in the absence of molecular oxygen and ammonium under constant bulb light illumination. Terpene accumulation was determined in the late stationary growth phase by analyzing $n$-dodecane samples via GC-FID measurements. The increase of $\beta$-caryophyllene production in tested $R$. capsulatus strains is shown in Figure 1 as relative values using $R$. capsulatus SB1003 solely carrying the plasmid-encoded QHS1 gene as reference strain.

As shown in Figure 1, the expression of the $\beta$-caryophyllene synthase gene QHS1 in $R$. capsulatus strain SB1003 led to a measurable production of $\beta$-caryophyllene. Remarkably, the co-expression of QHS1 and ispA in the R. capsulatus strain SB1003 as well as QHS1 expression in the engineered SB1003-MVA strain did not result in increased $\beta$-caryophyllene synthesis. However, concerted expression of QHS1 and ispA in R. capsulatus SB1003-MVA led to a considerable increase of sesquiterpenoid production of about $300 \%$ in comparison to the reference strain.

\subsection{Optimization of $\beta$-Caryophyllene Production in R. capsulatus via Modification of Cultivation Conditions}

In the above-described experiments, we could demonstrate that modular engineering of the isoprenoid biosynthesis can also be applied to improve $\beta$-caryophyllene production in $R$. capsulatus. Next, we analyzed whether the modification of cultivation conditions including a prolonged cultivation time or the change of illumination parameters can further improve the product yield in the better-performing strain SB1003-MVA. First, $\beta$-caryophyllene accumulation was comparatively analyzed over five days in photoheterotrophically-grown cultures of $R$. capsulatus strain SB1003-MVA carrying pRhon5Hi-2-QHS1 or pRhon5Hi-2-QHS1ispA. Product formation was determined by analyzing the overlaid $n$-dodecane samples via GC-FID measurements (Figure 2, blue bars). 


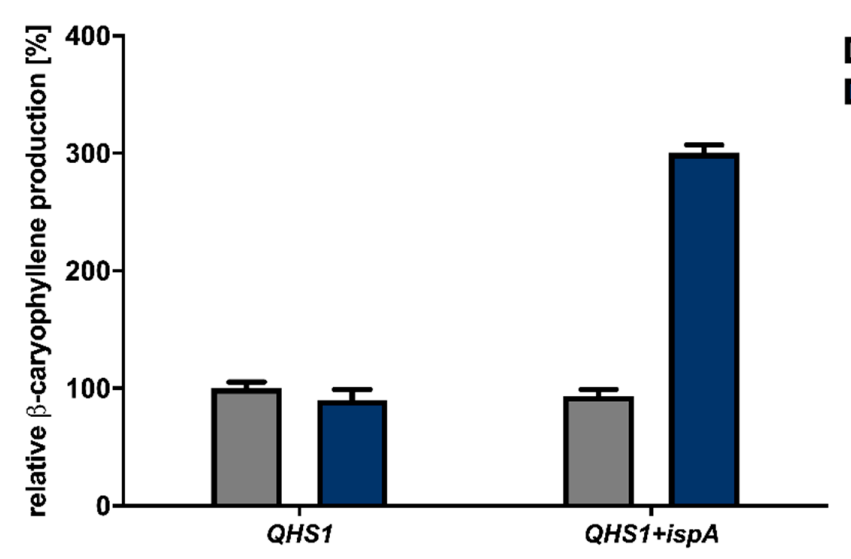

Figure 1. Heterologous $\beta$-caryophyllene production in the R. capsulatus strains SB1003 and SB1003MVA. The $\beta$-caryophyllene synthase gene QHS1 from A. annua was expressed in R. capsulatus SB1003 wild type (grey bars) and SB1003-MVA (blue bars), which additionally carries the MVA gene cluster from P. zeaxanthinifaciens to enable a second isoprenoid biosynthesis route. Moreover, the isp $A$ gene encoding the $R$. capsulatus FPP synthase was co-expressed on the same plasmid to further enhance sesquiterpene production titers. Product formation was determined in cell cultures after three days of photoheterotrophic cultivation (gas-tight hungate tubes, $30^{\circ} \mathrm{C}$ ) under ammonium depletion and constant illumination with bulb light $\left(3.6 \mathrm{~mW} \mathrm{~cm} \mathrm{c}^{-2}\right.$ at $\left.850 \mathrm{~nm}\right)$. The produced $\beta$-caryophyllene was sampled in overlaid $n$-dodecane phases for GC-FID analysis. The increase of $\beta$-caryophyllene production in engineered $R$. capsulatus strains is shown as relative values. To this end, the R. capsulatus SB1003 carrying the plasmid-encoded QHS1 gene was used as a reference strain. Values are means of three independent biological replicates $(n=3)$ and error bars indicate the respective standard deviations.

The highest product levels could be detected after three days of cultivation, where cells have typically reached the beginning of the stationary growth phase. The elongation of the cultivation time did not show increased product accumulation so that all further production experiments were carried out for three days. Under standard phototrophic conditions, conventional light bulbs are used for the illumination of $R$. capsulatus cells $[39,49]$. This conventional light source offers a broad emission spectrum with a relatively high proportion in the infrared (IR) light range $\left(>750 \mathrm{~nm} ; 3.6 \mathrm{~mW} \mathrm{~cm}^{-2}\right.$ at $\left.850 \mathrm{~nm}\right)$ suitable for excitation of bacteriochlorophyll $a$ (BChl $a$ ) exhibiting excitation maxima at 800 and $860 \mathrm{~nm}$ (Figure S6, Supplementary Materials, Reference [91]). To improve the illumination conditions for sesquiterpene production under phototrophic conditions, we subsequently analyzed if the use of (i) alternative cultivation vessels offering a better light penetration of cell cultures by a more favorable surface-area-to-volume ratio (Table S2, Supplementary Materials) or (ii) a customized IR-LED array $\left(5.6 \mathrm{~mW} \mathrm{~cm}^{-2}\right.$ at $\left.850 \mathrm{~nm}\right)$ suitable for specific excitation of the photopigment $\mathrm{BChl} a$ with high light intensities can help to increase product formation.

To investigate the influence of illumination conditions on the heterologous production of $\beta$-caryophyllene, the strain SB1003-MVA carrying the expression vector pRhon5Hi2-QHS1-ispA was cultivated over three days under photoheterotrophic conditions and constant illumination with bulb light or IR light in an ammonium-depleted medium in screw neck vials. As shown in Figure 2, the change of cultivation vessel geometry resulted only in a slight increase of $\beta$-caryophyllene production of $R$. capsulatus SB1003-MVA (pRhon5Hi-2-QHS1-ispA), whereas high irradiation with IR light led to a 1.9-fold increase of the final product accumulation. These results indicate that the applied illumination conditions should be taken into account to reach high product yields when $R$. capsulatus is used as an alternative terpene production host. This assumption is further supported by the observation that product levels were much lower in $R$. capsulatus SB1003-MVA (pRhon5Hi2-QHS1-ispA) cultures that have been grown under non-phototrophic, i.e., microaerobic conditions (Figure 2, green bars). For non-phototrophic cultivation, R. capsulatus SB1003MVA (pRhon5Hi-2-QHS1-ispA) was grown in $100 \mathrm{~mL}$, unbaffled shake flasks containing different volumes of medium in the dark to implement different aeration conditions 
(green bars). Those conditions could lead to the formation of $\beta$-caryophyllene oxide, the oxygenated derivative of $\beta$-caryophyllene. As previously described, a filling volume of $60 \mathrm{~mL}$ is most suitable for the induction of intrinsic terpene formation and $\mathrm{P}_{n i f}$-mediated target gene expression in R. capsulatus [39], which is corroborated by the observed $\beta$ caryophyllene production levels. Nevertheless, only a quarter of the product yield could be achieved under microaerobic, non-phototrophic growth conditions when compared to the corresponding values of phototrophically grown cells (R. capsulatus SB1003-MVA, pRhon5Hi-2-QHS1-ispA, 3 days, bulb light), and only traces of the oxygenated derivative were detectable (data not shown). However, to fully understand the effects of varying cultivation conditions on $\beta$-caryophyllene production, further experiments have to be performed in future studies.

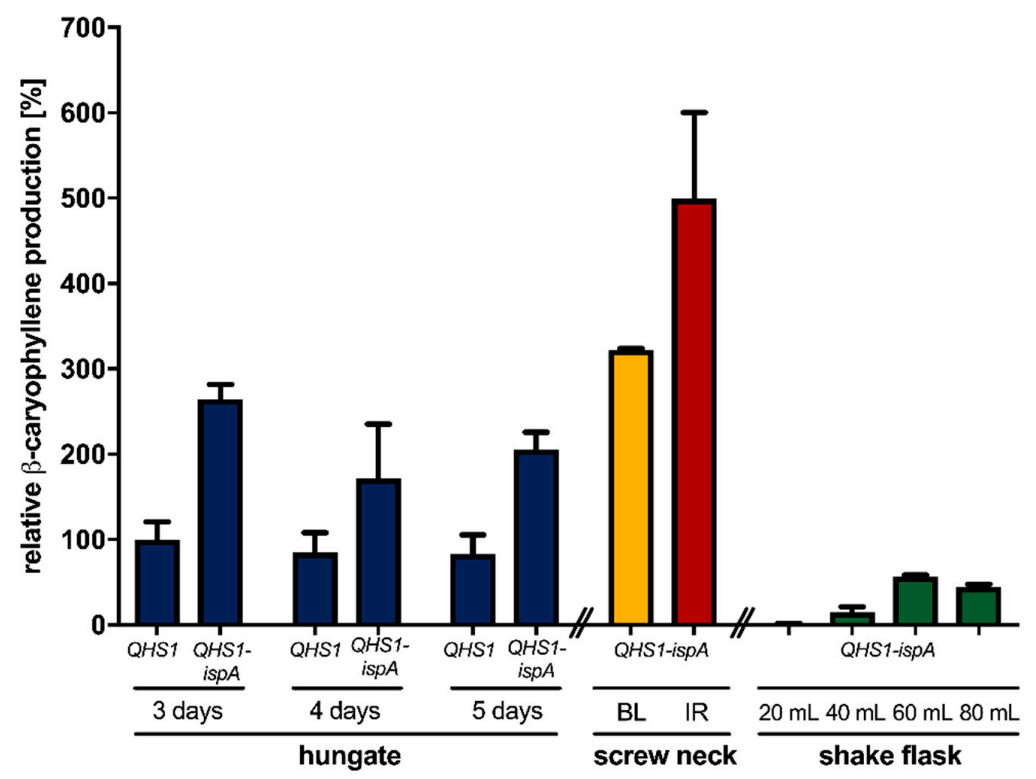

Figure 2. Heterologous $\beta$-caryophyllene production in the $R$. capsulatus strain SB1003-MVA with dependence on the cultivation time and illumination conditions. The $\beta$-caryophyllene accumulation was determined in $R$. capsulatus QHS1 expression strains SB1003-MVA (pRhon5Hi-2-QHS1) and SB1003-MVA (pRhon5Hi-2-QHS1-ispA). First, product formation was determined in cell cultures after three, four, and five days of photoheterotrophic cultivation in $15 \mathrm{~mL}$ hungate tubes using standard illumination conditions (bulb lights, $3.6 \mathrm{~mW} \mathrm{~cm}^{-2}$ at $850 \mathrm{~nm}$ ) and RCV medium supplemented with $0.1 \%$ serine. Blue bars represent the results of this experiment. Second, illumination conditions were changed by cultivating R. capsulatus strain SB1003-MVA (pRhon5Hi-2-QHS1-ispA) for three days under photoheterotrophic conditions using either constant illumination with bulb lights (BL; $3.6 \mathrm{~mW} \mathrm{~cm}^{-2}$ at $850 \mathrm{~nm}$, yellow bar) or IR-emitting diodes (IR; $5.6 \mathrm{~mW} \mathrm{~cm}^{-2}$ at $850 \mathrm{~nm}$, red bar). Here, $4.5-\mathrm{mL}$ screw neck vials were used to improve light penetration due to a more favorable surfacearea-to-volume ratio of this cultivation vessel. For non-phototrophic cultivation, the same strain was grown in 100-mL, unbaffled shake flasks containing different volumes of serine-supplemented RCV medium (shake flask, green bars). In all cultures, the produced $\beta$-caryophyllene was sampled in overlaid $n$-dodecane phases for GC-FID analysis. The increase of $\beta$-caryophyllene production is shown as relative values using $R$. capsulatus SB1003-MVA carrying the QHS1 expression plasmid pRhon5Hi-2-QHS1 as a reference strain. Values are the means of three independent biological replicates $(n=3)$ and the error bars indicate the respective standard deviations.

To accurately determine the final product titers, we analyzed (i) the individual transfer efficiency of $\beta$-caryophyllene from intact cells into the $n$-dodecane phase, (ii) the effect of the ICM, which is formed by R. capsulatus cells under phototrophic conditions, on sesquiterpenoid extraction, (iii) the differences in terpene transfer efficiencies when comparing single and repeated $n$-dodecane extraction, and finally (iv) the effect of the presence and absence 
of organic solvent on the final product titers (Supplementary Method section "Analysis of $n$-dodecane-mediated $\beta$-caryophyllene extraction from phototrophically grown $R$. capsulatus"). Finally, we were able to determine a product titer of $90 \pm 19 \mathrm{mg} \mathrm{L}^{-1} \beta$-caryophyllene for $R$. capsulatus SB1003-MVA with pRhon5Hi-2-QHS1-ispA after 3 days of cultivation in hungate tubes under bulb light. This titer could be further increased by using IR light and screw neck vials for cultivation, reaching a final product titer of $139 \pm 31 \mathrm{mg} \mathrm{L}^{-1}$. Based on these values and the reached cell densities, the respective productivities were further calculated (Table S3, Supplementary Materials).

In summary, we showed that $R$. capsulatus can efficiently synthesize the sesquiterpene $\beta$-caryophyllene. Furthermore, the modular adaptation of precursor gene expression under phototrophic growth conditions as well as the adjustment of cultivation conditions resulted in an increased sesquiterpenoid formation.

\subsection{Evaluation of Bioactivities of $\beta$-Caryophyllene and $\beta$-Caryophyllene Oxide against Different Phytopathogenic Organisms}

The agricultural industry is affected by a dwindling number of effective antimicrobial substances. On the other hand, farmers have to control plant pathogenic organisms without damaging non-target organisms. As $\beta$-caryophyllene and $\beta$-caryophyllene oxide offer a variety of beneficial bioactivities [70,79,92-95], we evaluated the potential use of those two sesquiterpenes as a nature-derived fungicide. To this end, we analyzed the activity against different phytopathogenic fungi, as well as various plant growth-promoting bacteria (PGPB).

3.3.1. Bioactivities of $\beta$-Caryophyllene and $\beta$-Caryophyllene Oxide against Phytopathogenic Fungi

We investigated the bioactivity of $\beta$-caryophyllene and $\beta$-caryophyllene oxide, which can be formed spontaneously by uncatalyzed processes [96,97], against the plant pathogenic fungi S. sclerotiorum, F. oxysporum, A. brassicicola, P. lingam, and R. solani. This analysis would additionally reveal whether the compound's oxygenation influences potential antifungal properties. Therefore, PDA agar plates were supplemented with increasing concentrations of both compounds, fungal discs were transferred onto these plates and fungal growth was determined. Evaluation revealed that the degree of growth inhibition due to direct terpene exposure varied depending on the compound and the fungus (Figure 3).

Both compounds inhibited the hyphal growth of $S$. sclerotiorum when compared to the solvent control. The inhibition reached up to $30 \%$ when the fungus was exposed to $\beta$ caryophyllene, while it was up to $40 \%$ when the fungus was cultivated on medium containing $\beta$-caryophyllene oxide. The effect against $F$. oxysporum was less pronounced. Around $20 \%$ inhibition was observed when the fungus was cultivated on the $\beta$-caryophyllenesupplemented medium, while it was around $30 \%$ in the case of $\beta$-caryophyllene oxide. Finally, the presence of $\beta$-caryophyllene in the growth medium slightly inhibited the growth of $A$. brassicicola while inhibition was higher and reached a maximum of $10 \%$ when $\beta$-caryophyllene oxide was used. No significant effect of both compounds was observed against $P$. lingam and $R$. solani (Figure S7, Supplementary Materials). Our results thus reveal that $\beta$-caryophyllene and its oxidized form possess antifungal activity against certain phytopathogenic fungi and that $\beta$-caryophyllene oxide tends to be more effective in inhibiting fungal growth. 
A

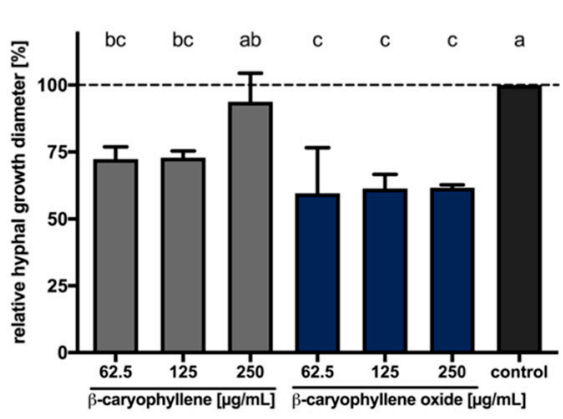

C

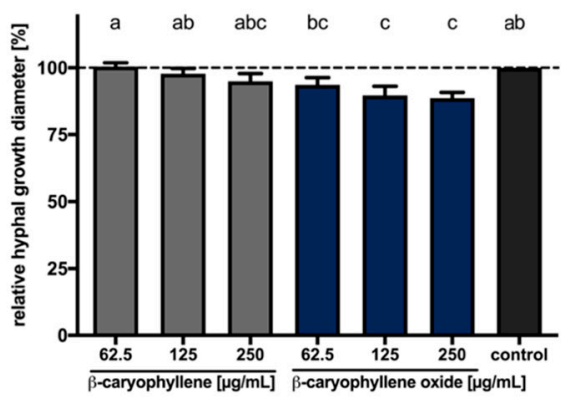

B

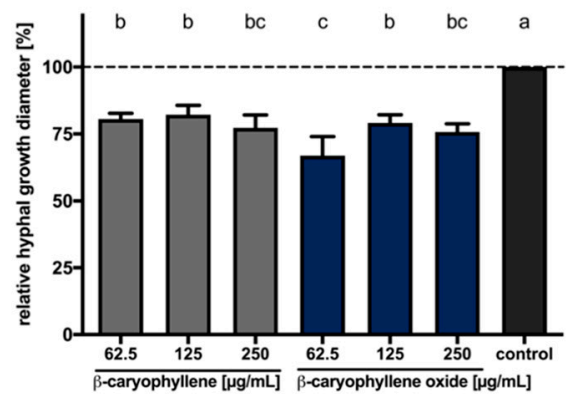

Figure 3. The effect of $\beta$-caryophyllene and $\beta$-caryophyllene oxide on the hyphal growth of plant pathogenic fungi. The effect of $\beta$-caryophyllene and $\beta$-caryophyllene oxide against $S$. sclerotiorum (A), F. oxysporum (B) and A. brassicicola (C). Final concentrations of $62.5 \mu \mathrm{g} \mathrm{mL}^{-1}, 125 \mu \mathrm{gL}^{-1}$, and 250 $\mu \mathrm{g} \mathrm{mL^{-1 }}$ of $\beta$-caryophyllene (grey bars) and $\beta$-caryophyllene oxide (blue bars) in PDA growth medium were used. Medium mixed with the solvents DMSO and Tween 20 (final concentrations, $0.5 \%$ and $1 \% v / v$, respectively) was used as the control (black bars). An equally sized disk with fungal mycelium was placed in the center of each plate and incubated for seven days at $24^{\circ} \mathrm{C}$. Subsequently, the diameter of each fungal colony was measured, and the relative growth compared to the solvent control was calculated. Each bar represents the mean \pm standard deviation of three independent biological measurements with three technical replicates each $(n=9)$. Different letters on the top of the bars indicate significant differences between the treatments based on ANOVA and Holm-Sidak post-hoc method $(p<0.05)$, while the same letters represent no significant differences.

\subsubsection{Antimicrobial Activities against Plant Growth-Promoting Bacteria}

As the previous investigations showed antifungal properties against several phytopathogenic fungi, the use of the sesquiterpenoids as natural compound-based plant protection products could be considered. To investigate potential toxic off-target effects on bacteria that promote plant growth, we next examined whether the addition of $\beta$ caryophyllene/oxide affects the growth of bacteria at concentrations used in the hyphal growth assay. For this purpose, the growth of representatives of the plant growth-promoting bacteria (PGPB) group [98-100], including the two diazotrophic bacteria Rhizobium rhizogenes and Rhodobacter capsulatus [101,102], the two bacilli Bacillus subtilis $[103,104]$ and Paenibacillus polymyxa [105], as well as the pseudomonads Pseudomonas fluorescens [104] and Pseudomonas putida [106] was analyzed in presence of $\beta$-caryophyllene and $\beta$-caryophyllene oxide. Both compounds were added to diluted bacterial cultures in increasing concentrations. After overnight incubation, the MICs were determined according to the respective optical density of the cell cultures (Figure 4).

The bacteria $R$. rhizogenes, $R$. capsulatus, B. subtilis, and P. polymyxa did not show reduced cell growth in comparison to the solvent control upon the addition of the two terpenes $\beta$-caryophyllene and $\beta$-caryophyllene oxide (Figure 4A-D). These bacteria showed an increase in growth, which could be explained by the metabolization of the terpenes. For $P$. putida, no effect of $\beta$-caryophyllene oxide was detected compared to the solvent control (Figure 4F). $\beta$-caryophyllene showed an influence on P. putida, which was concentration independent since all tested concentrations led to comparable cell growth. The cell densi- 
ties were about $40 \%$ lower compared to the solvent control. This effect was also observed for $P$. fluorescens, where the two terpenes reduced growth by up to $40 \%$ (Figure $4 \mathrm{E}$ ).

A

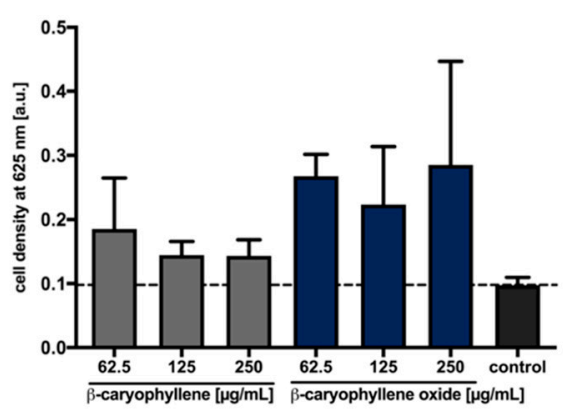

C

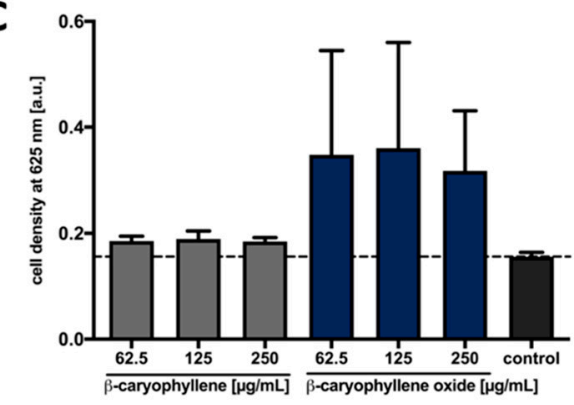

E

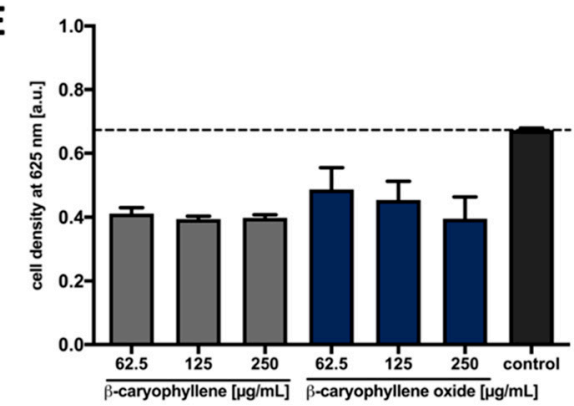

B

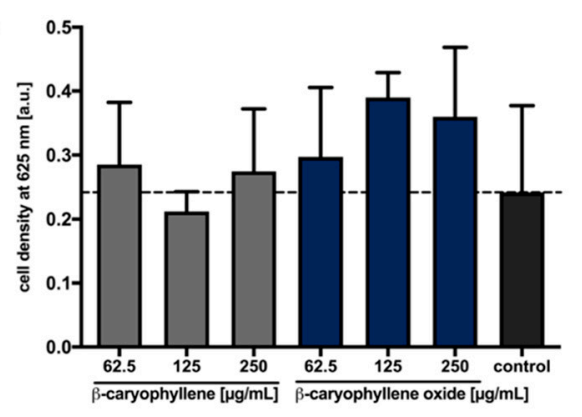

D

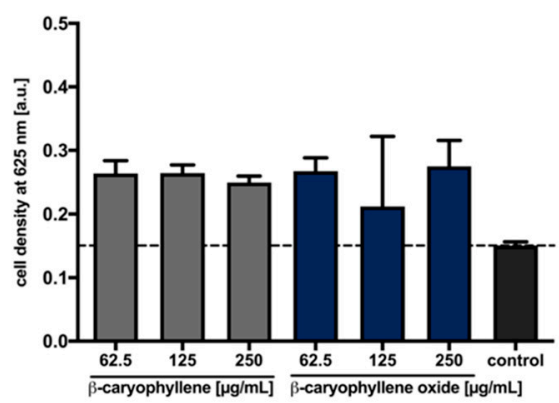

$\mathbf{F}$

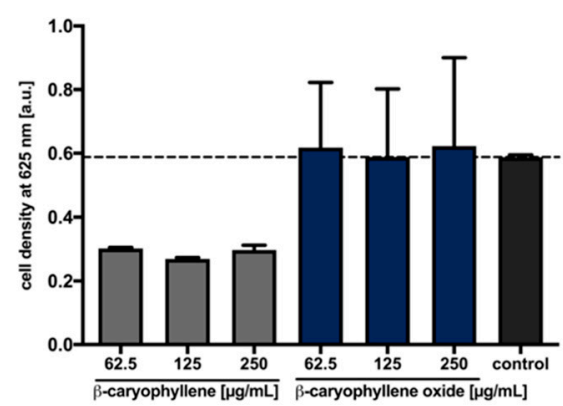

Figure 4. The influence of $\beta$-caryophyllene and $\beta$-caryophyllene oxide on the growth of plant growth-promoting bacteria. Final concentrations of $62.5 \mu \mathrm{g} \mathrm{mL}^{-1}, 125 \mu \mathrm{g} \mathrm{mL}^{-1}$ and $250 \mu \mathrm{g} \mathrm{mL}^{-1}$ of $\beta$-caryophyllene (grey bars) and $\beta$-caryophyllene oxide (blue bars) were added to cultures of R. rhizogenes (A), R. capsulatus (B), B. subtilis (C), P. polymyxa (D), P. fluorescens (E) and P. putida (F) in $100 \mu \mathrm{L} \mathrm{MH}$ medium (R. capsulatus in RCV medium) in MTPs. The final solvent concentration was $1 \%(v / v)$ Tween 20 and $0.5 \%(v / v)$ DMSO. To determine the influence of the terpenes on the growth of the bacteria, the cells were incubated stationary for $20 \mathrm{~h}$ at $37^{\circ} \mathrm{C}\left(\mathrm{R}\right.$. capsulatus at $\left.30^{\circ} \mathrm{C}\right)$ and the cell density was measured at $625 \mathrm{~nm}$ using a plate photometer. The solvent control (control, black bars) was MH or RCV medium containing 1\% (v/v) Tween 20 and 0.5\% (v/v) DMSO. Values are means of three independent biological replicates $(n=3)$ and error bars indicate the respective standard deviations.

In summary, for $\beta$-caryophyllene and $\beta$-caryophyllene oxide, no MIC could be determined for any of the tested PGPB, but a reduction of cell growth could be observed for both Pseudomonads. As a diverse group of different representative soil bacteria was tested, the results nevertheless indicate that $\beta$-caryophyllene and $\beta$-caryophyllene oxide do not exhibit strong broad-spectrum antibacterial activities at concentrations which considerably inhibit the hyphal growth of $S$. sclerotiorum and F. oxysporum $\left(63 \mu \mathrm{g} \mathrm{mL}^{-1}\right)$.

\section{Discussion}

The management of plant pathogens in the process of crop production is crucial, no matter whether organic, integrated, or conventional farming practices are applied. 
For many decades, synthetic pesticides were considered the fastest and most effective pest and pathogen control method. Recently, due to the rise of public health concerns about pesticide toxicity and harm to the environment, many of these effective chemicals were banned, thereby markedly limiting the options for plant protection. Therefore, it is important to find environmentally safe and sustainable natural products to control pathogens and thus ensure yield and food quality. In this context, plant metabolites are a rich source of bioactive compounds explorable for the use of preventing and controlling plant pathogenic microbes. In the last decade, several studies investigated terpenoids as potential antiphytopathogenic compounds $[67,71,76,77,107,108]$. $\beta$-caryophyllene is a natural bicyclic sesquiterpene that is a constituent of many essential oils. Many studies showed that these essential oils, which are containing $\beta$-caryophyllene as one of the main ingredients, are active against plant pathogens [109-111]. For example, methanol extracts from Artemisia annua leaves, one of the common $\beta$-caryophyllene producers, strongly inhibit the growth of the plant pathogenic fungi F. oxysporum and Fusarium solani [79]. In another study, the essential oil from Murraya paniculata leaves showed inhibitory activities on the mycelial growth of S. sclerotiorum, a fungus that poses a high risk to several crops. The gas chromatography analysis of the essential oil composition introduced $\beta$-caryophyllene as one of the main constituents (23.8\%) [109]. Furthermore, essential oils from Piper aduncum, which also has $\beta$-caryophyllene as one of its main constituents (7.2\%), inhibited the mycelial growth of the fungus S. sclerotiorum [110]. As a second alternative or complementary means for plant protection, there is also a multitude of important and useful microorganisms that support plant growth, which are called plant growth-promoting bacteria and plant growth-promoting fungi (PGPF). To offset the negative effects of chemical substances or make their use superfluous, more and more PGPB are now being used in agriculture [112]. Microorganisms can fulfill different functions in this process. Bacillus subtilis, for example, accumulates at the root system during the germination of various plants and prevents competing harmful fungi from spreading [103]. Diazotrophic organisms can supply plants with biologically available nitrogen by fixing atmospheric dinitrogen, thus making it available to the plants [113]. When fighting phytopathogens, it is important to consider and ideally avoid negative off-target effects on the above-mentioned beneficial microorganisms. Corresponding tests are therefore now frequently included in the first evaluation of antimicrobial activities.

So far, no studies were investigating the effect of pure $\beta$-caryophyllene and $\beta$-caryophyllene oxide against a selection of phytopathogenic fungi aiming to determine and compare the potential antifungal properties of the two compounds and species-specific differences in sensitivity. In our current study, we show the potential of sustainable production of $\beta$-caryophyllene in the heterologous host Rhodobacter capsulatus and the speciesspecific promoting or inhibitory effects for selected plant growth-promoting bacteria for both of the tested sesquiterpenoids at appropriate compound concentrations. Furthermore, we tested the bioactivities of both $\beta$-caryophyllene and $\beta$-caryophyllene oxide against several plant pathogenic fungi and showed that both substances were active against certain fungi. Interestingly, the oxidized form tended to be even more effective, and additionally has a more beneficial activity profile concerning the PGPB. These results are supported by previous reports which are introducing $\beta$-caryophyllene as a bioactive compound in its purified form [79] and as a component of several essential oils [109,110]. The purified $\beta$-caryophyllene showed a MIC of $130 \mu \mathrm{g} \mathrm{mL}{ }^{-1}$ for F. oxysporum [79], which is below the maximal concentration tested in this study. However, our plate-based approach is not completely comparable with the method used for MIC determination in liquid medium. According to our results, the inhibitory effect of the hyphal growth was different depending on the tested fungus. Such a difference is dependent on the fungal species and frequently described by previous studies showing that the novel fungicide 3-[5-(4-chlorophenyl)2,3-dimethyl-3-isoxazolidinyl] pyridine (SYP-Z048) affected several pathogenic fungi in different ways [114]. Overall, our current results demonstrate that both $\beta$-caryophyllene and $\beta$-caryophyllene oxide exhibit bioactivity against plant pathogenic fungi and therefore 
could be suitable as potential fungicides in agriculture as, in contrast to many broadspectrum pesticides, they do not harm many species of plant growth-promoting bacteria. However, despite the sesquiterpenes being natural compounds, which are often associated with non-harmful ecotoxicological profiles, effects against Pseudomonas species were corroborated and will need to be taken into account. So far, there is only limited information about the individual activities of terpenes against plant pathogens and the underlying molecular mechanisms. To be able to explain the differences we observed in the activity of the two terpenes against the different organisms and to get more data on the activity spectrum, our investigations need to be extended by including more target and non-target organisms. In addition, the respective modes of action on the molecular level have to be determined. Besides additional plant pathogens, this not only includes analyzing further plant growth-promoting bacteria, but it must be tested if plant growth-promoting fungi react sensitively to the terpenes, as indicated by a previous promising study [80]. In particular, fungi of the genus Trichoderma, which are said to have many advantageous properties for plants, could be investigated more closely [115,116].

To be able to provide appropriate quantities of an active antifungal substance, the heterologous production of promising sesquiterpenes in a suitable microbial host bears various benefits, such as the possibility to solely produce the desired compound without complex downstream processing and in high amounts. Therefore, we established the biosynthesis of the plant sesquiterpene $\beta$-caryophyllene in the heterologous production host $R$. capsulatus under phototrophic and non-phototrophic conditions. For this purpose, the intrinsic isoprenoid biosynthesis pathway was optimized in terms of its precursor supply. In particular, the $\mathrm{P}_{\text {nif }}$-based co-expression of isp $A$ and the genetically integrated MVA pathway resulted in a substantial increase in sesquiterpenoid production of around $300 \%$. These results are in agreement with previous studies, where engineering of isoprenoid precursor supply was a valuable tool to increase the terpenoid production in Rhodobacter $[38,40,48]$ and other bacterial hosts [23,117-125]. Also, we were able to increase the terpene production level further by changing the cultivation conditions from bulb light in a $14 \mathrm{~mL}$ hungate tube to IR light in a $4.5 \mathrm{~mL}$ screw neck vial, achieving a final $\beta$-caryophyllene titer of $139.29 \pm 31.35 \mathrm{mg} \mathrm{L}^{-1}$ and a specific productivity of $1.30 \pm 0.32 \mathrm{mg} \mathrm{g}^{-1}$ dry cells $\mathrm{h}^{-1}$. In recent studies, production titers around $220 \mathrm{mg} \mathrm{L}^{-1}$ [126] and specific productivities of $1.15 \mathrm{mg} \mathrm{g}^{-1}$ dry cells $\mathrm{h}^{-1}$ [127] were achieved in E. coli. Thus, we attained yields comparable to the current literature and successfully established $R$. capsulatus as a heterologous host for the production of $\beta$-caryophyllene. Furthermore, the $\beta$-caryophyllene yields achieved in $R$. capsulatus could be sufficient to use this host as a microbial system for in situ agent delivery. In the future, sesquiterpenoid producing $R$. capsulatus might thus be applicable as cell extracts with biocontrol activities for plant protection or as engineered antiphytopathogenic PGPB that can be added as live cultures to soils contained in vertical farming.

Supplementary Materials: The following are available online at https:/ / www.mdpi.com/2076-2 $607 / 9 / 1 / 168 /$ s1. Figure S1: Transfer efficiency of the $\beta$-caryophyllene reference compound from cultivation medium into the $n$-dodecane phase in the presence of intact $R$. capsulatus cells in hungate and screw neck vials, Figure S2: Transfer efficiency of the $\beta$-caryophyllene reference compound from cultivation medium into the $n$-dodecane phase in the presence of intact and disrupted $R$. capsulatus cells, Figure S3: Extraction efficiency of the $\beta$-caryophyllene reference compound from cultivation medium in the presence of disrupted and intact $R$. capsulatus cells by repeatedly using $n$-dodecane as organic solvent over four days, Figure S4: Comparison of relative $\beta$-caryophyllene formation in $R$. capsulatus production strains cultivated with and without an $n$-dodecane layer, Figure S5: Quantification of extracted $\beta$-caryophyllene via a calibration curve of $\beta$-caryophyllene reference signals in GC-FID analyses, Figure S6: Emission range of different light sources and the absorption spectrum of phototrophically cultivated $R$. capsulatus cells [128], Figure S7: Effect of $\beta$-caryophyllene and $\beta$-caryophyllene oxide on the hyphal growth of plant pathogenic fungi, Table S1: Bacterial strains and plasmids used in this study, Table S2: Cultivation vessel specifications, Table S3: Productivities of $\beta$-caryophyllene in $R$. capsulatus SB1003 cultures. 
Author Contributions: Conceptualization, T.D., A.L., K.-E.J., A.S.S.S., F.M.W.G.; methodology, F.H., Y.S.A., J.H.-H., A.H., S.S.H.; validation, F.H., S.S.H.; formal analysis, S.S.H., F.H.; investigation, F.H., S.S.H., Y.S.A., S.N., O.K.; writing-original draft preparation, F.H., S.S.H.; writing-review and editing, T.D., A.S.S.S., A.L., K.-E.J., F.M.W.G.; visualization, F.H.; supervision, T.D., A.L., A.S.S.S.; project administration, A.L., T.D., A.S.S.S., K.-E.J., F.M.W.G.; funding acquisition, A.L., T.D., A.S.S.S., K.-E.J., F.M.W.G. All authors have read and agreed to the published version of the manuscript.

Funding: The work was supported by grants from the Bioeconomy Science Center, and the European Regional Development Fund (ERDF: 34.EFRE-0300096) within the project CLIB-Kompetenzzentrum Biotechnologie CKB). The scientific activities of the Bioeconomy Science Center were financially supported by the Ministry of Innovation, Science and Research of the German federal state of North Rhine-Westphalia MIWF within the framework of the NRW Strategieprojekt BioSC (No. 313/323400-00213).

Institutional Review Board Statement: Not applicable.

Informed Consent Statement: Not applicable.

Data Availability Statement: The datasets generated and/or analyzed during the current study are available from the corresponding authors on reasonable request.

Acknowledgments: The authors would like to thank Olaf Cladders, Edwin Thiemann, Volker Neu, and Helmut Guenther from Vossloh-Schwabe Lighting Solutions GmbH \& Co. KG (Kamp-Lintfort, Germany) for their time, efforts and tremendous expertise in the LED array development thereby making the "illumination project" possible.

Conflicts of Interest: The authors declare no conflict of interest. The funders had no role in the design of the study, in the collection, analyzes, or interpretation of data, in the writing of the manuscript, or in the decision to publish the results.

\section{References}

1. Bian, G.; Deng, Z.; Liu, T. Strategies for terpenoid overproduction and new terpenoid discovery. Curr. Opin. Biotechnol. 2017, 48, 234-241. [CrossRef] [PubMed]

2. Christianson, D.W. Structural and Chemical Biology of Terpenoid Cyclases. Chem. Rev. 2017, 117, 11570-11648. [CrossRef] [PubMed]

3. Pemberton, T.A.; Chen, M.; Harris, G.G.; Chou, W.K.W.; Duan, L.; Köksal, M.; Genshaft, A.S.; Cane, D.E.; Christianson, D.W. Exploring the Influence of Domain Architecture on the Catalytic Function of Diterpene Synthases. Biochemistry 2017, 56, $2010-2023$. [CrossRef] [PubMed]

4. Wink, M. Modes of Action of Herbal Medicines and Plant Secondary Metabolites. Medicines 2015, 2, 251-286. [CrossRef]

5. Ruzicka, L. The isoprene rule and the biogenesis of terpenic compounds. Experientia 1953, 9, 357-367. [CrossRef]

6. Croteau, R.; Kutchan, T.M.; Lewis, N.G. Secondary Metabolites. Biochem. Mol. Biol. Plants 2000, 7, 1250-1318.

7. Boucher, Y.; Doolittle, W.F. The role of lateral gene transfer in the evolution of isoprenoid biosynthesis pathways. Mol. Microbiol. 2000, 37, 703-716. [CrossRef]

8. Frank, A.; Groll, M. The Methylerythritol Phosphate Pathway to Isoprenoids. Chem. Rev. 2017, 117, 5675-5703. [CrossRef]

9. Langenheim, J.H. Higher plant terpenoids: A phytocentric overview of their ecological roles. J. Chem. Ecol. 1994, 20, 1223-1280. [CrossRef]

10. Gershenzon, J.; Dudareva, N. The function of terpene natural products in the natural world. Nat. Chem. Biol. 2007, 3, 408-414. [CrossRef]

11. Pichersky, E.; Raguso, R.A. Why do plants produce so many terpenoid compounds? New Phytol. 2018, 220, 692-702. [CrossRef] [PubMed]

12. Efferth, T. From ancient herb to modern drug: Artemisia annua and artemisinin for cancer therapy. Semin. Cancer Biol. 2017, 46, 65-83. [CrossRef] [PubMed]

13. Mahizan, N.A.; Yang, S.-K.; Moo, C.-L.; Song, A.A.-L.; Chong, C.-M.; Chong, C.-W.; Abushelaibi, A.; Lim, S.-H.E.; Lai, K.-S. Terpene Derivatives as a Potential Agent against Antimicrobial Resistance (AMR) Pathogens. Molecules 2019, 24, 2631. [CrossRef] [PubMed]

14. Walencka, E.; Rozalska, S.; Wysokinska, H.; Rozalski, M.; Kuzma, L.; Rozalska, B. Salvipisone and aethiopinone from Salvia sclarea hairy roots modulate staphylococcal antibiotic resistance and express anti-biofilm activity. Planta Med. 2007, 73, 545-551. [CrossRef] [PubMed]

15. Jabra-Rizk, M.A.; Meiller, T.F.; James, C.E.; Shirtliff, M.E. Effect of farnesol on Staphylococcus aureus biofilm formation and antimicrobial susceptibility. Antimicrob. Agents Chemother. 2006, 50, 1463-1469. [CrossRef] [PubMed]

16. Gomes, F.I.A.; Teixeira, P.; Azeredo, J.; Oliveira, R. Effect of farnesol on planktonic and biofilm cells of Staphylococcus epidermidis. Curr. Microbiol. 2009, 59, 118-122. [CrossRef] [PubMed] 
17. Castelo-Branco, D.S.C.M.; Riello, G.B.; Vasconcelos, D.C.; Guedes, G.M.M.; Serpa, R.; Bandeira, T.J.P.G.; Monteiro, A.J.; Cordeiro, R.A.; Rocha, M.F.G.; Sidrim, J.J.C.; et al. Farnesol increases the susceptibility of Burkholderia pseudomallei biofilm to antimicrobials used to treat melioidosis. J. Appl. Microbiol. 2016, 120, 600-606. [CrossRef]

18. Malingre, T.; Hendriks, H.; Batterman, S.; Bos, R.; Visser, J. The Essential Oil of Cannabis sativa. Planta Med. 1975, 28, 56-61. [CrossRef]

19. De Vasconcelos Silva, M.; Craveiro, A.; Abreu Matos, F.; Machado, M.I.; Alencar, J. Chemical variation during daytime of constituents of the essential oil of Ocimum gratissimum leaves. Fitoterapia 1999, 70, 32-34. [CrossRef]

20. Matias, E.F.F.; Alves, E.F.; Silva, M.K.N.; Carvalho, V.R.A.; Figueredo, F.G.; Ferreira, J.V.A.; Coutinho, H.D.M.; Silva, J.M.F.L.; Ribeiro-Filho, J.; Costa, J.G.M. Seasonal variation, chemical composition and biological activity of the essential oil of Cordia verbenacea DC (Boraginaceae) and the sabinene. Ind. Crops Prod. 2016, 87, 45-53. [CrossRef]

21. Marienhagen, J.; Bott, M. Metabolic engineering of microorganisms for the synthesis of plant natural products. J. Biotechnol. 2013, 163, 166-178. [CrossRef]

22. Kallscheuer, N.; Classen, T.; Drepper, T.; Marienhagen, J. Production of plant metabolites with applications in the food industry using engineered microorganisms. Curr. Opin. Biotechnol. 2019, 56, 7-17. [CrossRef]

23. Schempp, F.M.; Drummond, L.; Buchhaupt, M.; Schrader, J. Microbial Cell Factories for the Production of Terpenoid Flavor and Fragrance Compounds. J. Agric. Food Chem. 2018, 66, 2247-2258. [CrossRef] [PubMed]

24. Pham, J.V.; Yilma, M.A.; Feliz, A.; Majid, M.T.; Maffetone, N.; Walker, J.R.; Kim, E.; Cho, H.J.; Reynolds, J.M.; Song, M.C.; et al. A Review of the Microbial Production of Bioactive Natural Products and Biologics. Front. Microbiol. 2019, 10, 1-27.

25. Cravens, A.; Payne, J.; Smolke, C.D. Synthetic biology strategies for microbial biosynthesis of plant natural products. Nat. Commun. 2019, 10, 2142.

26. Sgobba, E.; Wendisch, V.F. Synthetic microbial consortia for small molecule production. Curr. Opin. Biotechnol. 2020, 62, 72-79. [CrossRef] [PubMed]

27. Kirby, J.; Keasling, J.D. Metabolic engineering of microorganisms for isoprenoid production. Nat. Prod. Rep. 2008, 25, 656-661. [PubMed]

28. Mitchell, W. Natural products from synthetic biology. Curr. Opin. Chem. Biol. 2011, 15, 505-515. [CrossRef] [PubMed]

29. Chen, Y.; Zhou, Y.J.; Siewers, V.; Nielsen, J. Enabling technologies to advance microbial isoprenoid production. Adv. Biochem. Eng. Biotechnol. 2015, 148, 143-160.

30. Wong, J.; Rios-Solis, L.; Keasling, J.D. Microbial Production of Isoprenoids. In Consequences of Microbial Interactions with Hydrocarbons, Oils, and Lipids: Production of Fuels and Chemicals; Lee, S.Y., Ed.; Springer International Publishing: Cham, Switzerland, 2016; pp. 1-24. ISBN 978-3-319-31421-1.

31. Helfrich, E.J.N.; Lin, G.-M.; Voigt, C.A.; Clardy, J. Bacterial terpene biosynthesis: Challenges and opportunities for pathway engineering. Beilstein J. Org. Chem. 2019, 15, 2889-2906.

32. Chemler, J.A.; Koffas, M.A.G. Metabolic engineering for plant natural product biosynthesis in microbes. Curr. Opin. Biotechnol. 2008, 19, 597-605. [CrossRef] [PubMed]

33. Paddon, C.J.; Westfall, P.J.; Pitera, D.J.; Benjamin, K.; Fisher, K.; McPhee, D.; Leavell, M.D.; Tai, A.; Main, A.; Eng, D.; et al. High-level semi-synthetic production of the potent antimalarial artemisinin. Nature 2013, 496, 528-532. [CrossRef] [PubMed]

34. Atanasov, A.G.; Waltenberger, B.; Pferschy-Wenzig, E.-M.M.; Linder, T.; Wawrosch, C.; Uhrin, P.; Temml, V.; Wang, L.; Schwaiger, S.; Heiss, E.H.; et al. Discovery and resupply of pharmacologically active plant-derived natural products: A review. Biotechnol. Adv. 2015, 33, 1582-1614. [CrossRef]

35. Zhang, C.; Hong, K. Production of Terpenoids by Synthetic Biology Approaches. Front. Bioeng. Biotechnol. 2020, 8, 347. [CrossRef] [PubMed]

36. Yu, Y.; Rasool, A.; Liu, H.; Lv, B.; Chang, P.; Song, H.; Wang, Y.; Li, C. Engineering Saccharomyces cerevisiae for high yield production of $\alpha$-amyrin via synergistic remodeling of $\alpha$-amyrin synthase and expanding the storage pool. Metab. Eng. 2020, 62, 72-83. [CrossRef]

37. Bauer, K.; Garbe, D.; Surburg, H. Common Fragrance and Flavor Materials; Wiley-VCH: Weinheim, Germany, 2001.

38. Beekwilder, J.; van Houwelingen, A.; Cankar, K.; van Dijk, A.D.J.; de Jong, R.M.; Stoopen, G.; Bouwmeester, H.; Achkar, J.; Sonke, T.; Bosch, D. Valencene synthase from the heartwood of Nootka cypress (Callitropsis nootkatensis) for biotechnological production of valencene. Plant Biotechnol. J. 2014, 12, 174-182. [CrossRef]

39. Troost, K.; Loeschcke, A.; Hilgers, F.; Özgür, A.Y.; Weber, T.M.; Santiago-Schübel, B.; Svensson, V.; Hage-Hülsmann, J.; Habash, S.S.; Grundler, F.M.W.; et al. Engineered Rhodobacter capsulatus as a Phototrophic Platform Organism for the Synthesis of Plant Sesquiterpenoids. Front. Microbiol. 2019, 10, 1998. [CrossRef]

40. Orsi, E.; Folch, P.L.; Monje-López, V.T.; Fernhout, B.M.; Turcato, A.; Kengen, S.W.M.; Eggink, G.; Weusthuis, R.A. Characterization of heterotrophic growth and sesquiterpene production by Rhodobacter sphaeroides on a defined medium. J. Ind. Microbiol. Biotechnol. 2019, 46, 1179-1190. [CrossRef]

41. Lin, P.-C.; Pakrasi, H.B. Engineering cyanobacteria for production of terpenoids. Planta 2019, 249, 145-154. [CrossRef]

42. Das, A.; Yoon, S.-H.; Lee, S.-H.; Kim, J.-Y.; Oh, D.-K.; Kim, S.-W. An update on microbial carotenoid production: Application of recent metabolic engineering tools. Appl. Microbiol. Biotechnol. 2007, 77, 505-512. [CrossRef]

43. Arendt, P.; Miettinen, K.; Pollier, J.; De Rycke, R.; Callewaert, N.; Goossens, A. An endoplasmic reticulum-engineered yeast platform for overproduction of triterpenoids. Metab. Eng. 2017, 40, 165-175. [CrossRef] [PubMed] 
44. Tucker, J.D.; Siebert, C.A.; Escalante, M.; Adams, P.G.; Olsen, J.D.; Otto, C.; Stokes, D.L.; Hunter, C.N. Membrane invagination in Rhodobacter sphaeroides is initiated at curved regions of the cytoplasmic membrane, then forms both budded and fully detached spherical vesicles. Mol. Microbiol. 2010, 76, 833-847. [CrossRef] [PubMed]

45. Drews, G. The intracytoplasmic membranes of purple bacteria-Assembly of energy-transducing complexes. J. Mol. Microbiol. Biotechnol. 2013, 23, 35-47. [CrossRef] [PubMed]

46. Armstrong, G.A.; Alberti, M.; Leach, F.; Hearst, J.E. Nucleotide sequence, organization, and nature of the protein products of the carotenoid biosynthesis gene cluster of Rhodobacter capsulatus. Mol. Gen. Genet. MGG 1989, 216, 254-268. [CrossRef]

47. Armstrong, G.A. Genetics of eubacterial carotenoid biosynthesis: A colorful tale. Annu. Rev. Microbiol. 1997, 51, 629-659. [CrossRef]

48. Khan, N.E.; Nybo, S.E.; Chappell, J.; Curtis, W.R. Triterpene hydrocarbon production engineered into a metabolically versatile host-Rhodobacter capsulatus. Biotechnol. Bioeng. 2015, 112, 1523-1532. [CrossRef]

49. Loeschcke, A.; Dienst, D.; Wewer, V.; Hage-Hülsmann, J.; Dietsch, M.; Kranz-Finger, S.; Hüren, V.; Metzger, S.; Urlacher, V.B.; Gigolashvili, T.; et al. The photosynthetic bacteria Rhodobacter capsulatus and Synechocystis sp. PCC 6803 as new hosts for cyclic plant triterpene biosynthesis. PLOS ONE 2017, 12, e0189816. [CrossRef]

50. Orsi, E.; Beekwilder, J.; Peek, S.; Eggink, G.; Kengen, S.W.M.; Weusthuis, R.A. Metabolic flux ratio analysis by parallel 13C labeling of isoprenoid biosynthesis in Rhodobacter sphaeroides. Metab. Eng. 2020, 57, 228-238. [CrossRef]

51. Orsi, E.; Mougiakos, I.; Post, W.; Beekwilder, J.; Dompè, M.; Eggink, G.; Van Der Oost, J.; Kengen, S.W.M.; Weusthuis, R.A. Growth-uncoupled isoprenoid synthesis in Rhodobacter sphaeroides. Biotechnol. Biofuels 2020, 13. [CrossRef]

52. Orsi, E.; Beekwilder, J.; van Gelder, D.; van Houwelingen, A.; Eggink, G.; Kengen, S.W.M.; Weusthuis, R.A. Functional replacement of isoprenoid pathways in Rhodobacter sphaeroides. Microb. Biotechnol. 2020, 13, 1082-1093. [CrossRef]

53. Oerke, E.-C. Crop losses to pests. J. Agric. Sci. 2006, 144, 31-43. [CrossRef]

54. Bolton, M.D.; Thomma, B.P.H.J.; Nelson, B.D. Sclerotinia sclerotiorum (Lib.) de Bary: Biology and molecular traits of a cosmopolitan pathogen. Mol. Plant Pathol. 2006, 7, 1-16. [CrossRef] [PubMed]

55. Okungbowa, F.I.; Shittu, H.O. Fusarium wilts: An overview. Environ. Res. J. 2012, 6, 83-102.

56. West, J.S.; Kharbanda, P.D.; Barbetti, M.J.; Fitt, B.D.L. Epidemiology and management of Leptosphaeria maculans (phoma stem canker) on oilseed rape in Australia, Canada and Europe. Plant Pathol. 2001, 50, 10-27. [CrossRef]

57. Fitt, B.D.L.; Brun, H.; Barbetti, M.J.; Rimmer, S.R. World-Wide Importance of Phoma Stem Canker (Leptosphaeria maculans and L. biglobosa) on Oilseed Rape (Brassica napus). Eur. J. Plant Pathol. 2006, 114, 3-15. [CrossRef]

58. Singh, H.K.; Singh, R.B.; Kumar, P.; Singh, M.; Yadav, J.K.; Singh, P.K.; Chauhan, M.P.; Shakywar, R.C.; Maurya, K.N.; Priyanka, B.S.; et al. Alternaria blight of rapeseed mustard-A Review. J. Environ. Biol. 2017, 38, 1405-1420. [CrossRef]

59. Verma, P.R. Biology and control of Rhizoctonia solani on rapeseed: A Review. Phytoprotection 2005, 77, 99-111. [CrossRef]

60. Paulitz, T.C.; Okubara, P.A.; Schillinger, W.F. First Report of Damping-Off of Canola Caused by Rhizoctonia solani AG 2-1 in Washington State. Plant Dis. 2006, 90, 829. [CrossRef]

61. Bridge, J. Nematode management in sustainable and subsistence agriculture. Annu. Rev. Phytopathol. 1996, 34, 201-225. [CrossRef]

62. Heydari, A.; Pessarakli, M. A Review on Biological Control of Fungal Plant Pathogens Using Microbial Antagonists. J. Biol. Sci. 2010, 10, 273-290. [CrossRef]

63. Habash, S.; Al-Banna, L. Phosphonate fertilizers suppressed root knot nematodes Meloidogyne javanica and M. incognita. J. Nematol. 2011, 43, 95-100. [PubMed]

64. Timper, P. Conserving and enhancing biological control of nematodes. J. Nematol. 2014, 46, 75-89. [PubMed]

65. Lu, C.; Tian, H. Global nitrogen and phosphorus fertilizer use for agriculture production in the past half century: Shifted hot spots and nutrient imbalance. Earth Syst. Sci. Data 2017, 9, 181-192. [CrossRef]

66. Cheng, A.-X.; Xiang, C.-Y.; Li, J.-X.; Yang, C.-Q.; Hu, W.-L.; Wang, L.-J.; Lou, Y.-G.; Chen, X.-Y. The rice (E)- $\beta$-caryophyllene synthase (OsTPS3) accounts for the major inducible volatile sesquiterpenes. Phytochemistry 2007, 68, 1632-1641. [CrossRef] [PubMed]

67. Echeverrigaray, S.; Zacaria, J.; Beltrão, R. Nematicidal Activity of Monoterpenoids against the Root-Knot Nematode Meloidogyne incognita. Phytopathology 2010, 100, 199-203. [CrossRef]

68. Zengin, H.; Baysal, A.H. Antibacterial and antioxidant activity of essential oil terpenes against pathogenic and spoilage-forming bacteria and cell structure-activity relationships evaluated by SEM microscopy. Molecules 2014, 19, 17773-17798. [CrossRef]

69. Dambolena, J.S.; Zunino, M.P.; Herrera, J.M.; Pizzolitto, R.P.; Areco, V.A.; Zygadlo, J.A. Terpenes: Natural Products for Controlling Insects of Importance to Human Health-A Structure-Activity Relationship Study. Psyche A J. Entomol. 2016, $2016,1-17$. [CrossRef]

70. Araniti, F.; Sánchez-Moreiras, A.M.; Graña, E.; Reigosa, M.J.; Abenavoli, M.R. Terpenoid trans -caryophyllene inhibits weed germination and induces plant water status alteration and oxidative damage in adult Arabidopsis. Plant Biol. 2017, 19, 79-89. [CrossRef]

71. Pungartnik, C. Antifungal Potential of Terpenes from Spondias Purpurea L. Leaf Extract against Moniliophthora perniciosa that causes Witches Broom Disease of Theobroma cacao. Int. J. Complement. Altern. Med. 2017, 7. [CrossRef]

72. Habash, S.S.; Könen, P.P.; Loeschcke, A.; Wüst, M.; Jaeger, K.-E.; Drepper, T.; Grundler, F.M.W.; Schleker, A.S.S. The Plant Sesquiterpene Nootkatone Efficiently Reduces Heterodera schachtii Parasitism by Activating Plant Defense. Int. J. Mol. Sci. 2020, 21, 9627. [CrossRef] 
73. Kigathi, R.N.; Unsicker, S.B.; Reichelt, M.; Kesselmeier, J.; Gershenzon, J.; Weisser, W.W. Emission of Volatile Organic Compounds After Herbivory from Trifolium pratense (L.) Under Laboratory and Field Conditions. J. Chem. Ecol. 2009, 35, 1335-1348. [CrossRef] [PubMed]

74. Pazouki, L.; Kanagendran, A.; Li, S.; Kännaste, A.; Rajabi Memari, H.; Bichele, R.; Niinemets, Ü. Mono- and sesquiterpene release from tomato (Solanum lycopersicum) leaves upon mild and severe heat stress and through recovery: From gene expression to emission responses. Environ. Exp. Bot. 2016, 132, 1-15. [CrossRef] [PubMed]

75. Muchlinski, A.; Chen, X.; Lovell, J.T.; Köllner, T.G.; Pelot, K.A.; Zerbe, P.; Ruggiero, M.; Callaway, L.; Laliberte, S.; Chen, F.; et al. Biosynthesis and Emission of Stress-Induced Volatile Terpenes in Roots and Leaves of Switchgrass (Panicum virgatum L.). Front. Plant Sci. 2019, 10, 1144. [CrossRef] [PubMed]

76. Huang, M.; Sanchez-Moreiras, A.M.; Abel, C.; Sohrabi, R.; Lee, S.; Gershenzon, J.; Tholl, D. The major volatile organic compound emitted from Arabidopsis thaliana flowers, the sesquiterpene (E)- $\beta$-caryophyllene, is a defense against a bacterial pathogen. New Phytol. 2012, 193, 997-1008. [CrossRef] [PubMed]

77. Rasmann, S.; Köllner, T.G.; Degenhardt, J.; Hiltpold, I.; Toepfer, S.; Kuhlmann, U.; Gershenzon, J.; Turlings, T.C.J. Recruitment of entomopathogenic nematodes by insect-damaged maize roots. Nature 2005, 434, 732-737. [CrossRef]

78. Degenhardt, J.; Hiltpold, I.; Kollner, T.G.; Frey, M.; Gierl, A.; Gershenzon, J.; Hibbard, B.E.; Ellersieck, M.R.; Turlings, T.C.J. Restoring a maize root signal that attracts insect-killing nematodes to control a major pest. Proc. Natl. Acad. Sci. USA 2009, 106, 13213-13218. [CrossRef]

79. Ma, Y.-N.; Chen, C.-J.; Li, Q.-Q.; Xu, F.-R.; Cheng, Y.-X.; Dong, X. Monitoring Antifungal Agents of Artemisia annua against Fusarium oxysporum and Fusarium solani, Associated with Panax notoginseng Root-Rot Disease. Molecules 2019, 24, 213. [CrossRef]

80. Yamagiwa, Y.; Inagaki, Y.; Ichinose, Y.; Toyoda, K.; Hyakumachi, M.; Shiraishi, T. Talaromyces wortmannii FS2 emits $\beta$-caryophyllene, which promotes plant growth and induces resistance. J. Gen. Plant. Pathol. 2011, 77, 336-341. [CrossRef]

81. Hanahan, D. Studies on transformation of Escherichia coli with plasmids. J. Mol. Biol. 1983, 166, 557-580. [CrossRef]

82. Simon, R.; Priefer, U.; Pühler, A. A Broad Host Range Mobilization System for In Vivo Genetic Engineering: Transposon Mutagenesis in Gram Negative Bacteria. Bio/Technology 1983, 1, 784-791. [CrossRef]

83. Strnad, H.; Lapidus, A.; Paces, J.; Ulbrich, P.; Vlcek, C.; Paces, V.; Haselkorn, R. Complete genome sequence of the photosynthetic purple nonsulfur bacterium Rhodobacter capsulatus SB1003. J. Bacteriol. 2010, 192, 3545-3546. [CrossRef] [PubMed]

84. Klipp, W.; Masepohl, B.; Pühler, A. Identification and mapping of nitrogen fixation genes of Rhodobacter capsulatus: Duplication of a nifA-nifB region. J. Bacteriol. 1988, 170, 693-699. [CrossRef] [PubMed]

85. Weaver, P.F.; Wall, J.D.; Gest, H. Characterization of Rhodopseudomonas capsulata. Arch. Microbiol. 1975, 105, 207-216. [CrossRef] [PubMed]

86. Fuhrmann, M.; Hausherr, A.; Ferbitz, L.; Schödl, T.; Heitzer, M.; Hegemann, P. Monitoring dynamic expression of nuclear genes in Chlamydomonas reinhardtii by using a synthetic luciferase reporter gene. Plant Mol. Biol. 2004, 55, 869-881. [CrossRef] [PubMed]

87. Hungate, R.E. Chapter IV A Roll Tube Method for Cultivation of Strict Anaerobes; Norris, J.R., Ribbons, D.W.B.T.-M., Eds.; Academic Press: Cambridge, MA, USA, 1969; Volume 3, pp. 117-132.

88. Rodriguez, S.; Kirby, J.; Denby, C.M.; Keasling, J.D. Production and quantification of sesquiterpenes in Saccharomyces cerevisiae, including extraction, detection and quantification of terpene products and key related metabolites. Nat. Protoc. 2014, 9, 1980-1996. [CrossRef]

89. Wiegand, I.; Hilpert, K.; Hancock, R.E.W. Agar and broth dilution methods to determine the minimal inhibitory concentration (MIC) of antimicrobial substances. Nat. Protoc. 2008, 3, 163-175. [CrossRef]

90. European Committee for Antimicrobial Susceptibility Testing (EUCAST) of the European Society of Clinical Microbiology and Infectious Diseases (ESCMID). Determination of minimum inhibitory concentrations (MICs) of antibacterial agents by broth dilution. Clin. Microbiol. Infect. 2003, 9, ix-xv. [CrossRef]

91. Kim, S.; Jahandar, M.; Jeong, J.H.; Lim, D.C. Recent Progress in Solar Cell Technology for Low-Light Indoor Applications. Curr. Altern. Energy 2019, 3, 3-17. [CrossRef]

92. Ruberto, G.; Baratta, M.T. Antioxidant activity of selected essential oil components in two lipid model systems. Food Chem. 2000, 69, 167-174. [CrossRef]

93. Medeiros, R.; Passos, G.F.; Vitor, C.E.; Koepp, J.; Mazzuco, T.L.; Pianowski, L.F.; Campos, M.M.; Calixto, J.B. Effect of two active compounds obtained from the essential oil of Cordia verbenacea on the acute inflammatory responses elicited by LPS in the rat paw. Br. J. Pharmacol. 2007, 151, 618-627. [CrossRef]

94. Fidyt, K.; Fiedorowicz, A.; Strządała, L.; Szumny, A. $\beta$-caryophyllene and $\beta$-caryophyllene oxide-natural compounds of anticancer and analgesic properties. Cancer Med. 2016, 5, 3007-3017. [CrossRef] [PubMed]

95. Paula-Freire, L.I.G.; Andersen, M.L.; Gama, V.S.; Molska, G.R.; Carlini, E.L.A. The oral administration of trans-caryophyllene attenuates acute and chronic pain in mice. Phytomedicine 2014, 21, 356-362. [CrossRef] [PubMed]

96. Sköld, M.; Karlberg, A.-T.; Matura, M.; Börje, A. The fragrance chemical $\beta$-caryophyllene-Air oxidation and skin sensitization. Food Chem. Toxicol. 2006, 44, 538-545. [CrossRef] [PubMed]

97. Steenackers, B.; Neirinckx, A.; De Cooman, L.; Hermans, I.; De Vos, D. The strained sesquiterpene $\beta$-caryophyllene as a probe for the solvent-assisted epoxidation mechanism. ChemPhysChem 2014, 15, 966-973. [CrossRef]

98. De Souza, R.; Ambrosini, A.; Passaglia, L.M.P. Plant growth-promoting bacteria as inoculants in agricultural soils. Genet. Mol. Biol. 2015, 38, 1678-4685. [CrossRef] 
99. Nath Yadav, A. Plant Growth Promoting Bacteria: Biodiversity and Multifunctional Attributes for Sustainable Agriculture. Adv. Biotechnol. Microbiol. 2017, 5. [CrossRef]

100. Singh, V.K.; Singh, A.K.; Singh, P.P.; Kumar, A. Interaction of plant growth promoting bacteria with tomato under abiotic stress: A review. Agric. Ecosyst. Environ. 2018, 267, 129-140. [CrossRef]

101. Çakmakçi, R.; Dönmez, F.; Aydin, A.; Şahin, F. Growth promotion of plants by plant growth-promoting rhizobacteria under greenhouse and two different field soil conditions. Soil Biol. Biochem. 2006, 38, 1482-1487. [CrossRef]

102. Çakmakçi, R.; Dönmez, M.F.; Erdoǧan, Ü. The effect of plant growth promoting rhizobacteria on Barley seedling growth, nutrient uptake, some soil properties, and bacterial counts. Turk. J. Agric. For. 2007, 31, 189-199.

103. Lahlali, R.; Peng, G.; Gossen, B.D.; McGregor, L.; Yu, F.Q.; Hynes, R.K.; Hwang, S.F.; McDonald, M.R.; Boyetchko, S.M. Evidence that the Biofungicide Serenade (Bacillus subtilis) Suppresses Clubroot on Canola via Antibiosis and Induced Host Resistance. Phytopathology 2012, 103, 245-254. [CrossRef]

104. Berg, G. Plant-microbe interactions promoting plant growth and health: Perspectives for controlled use of microorganisms in agriculture. Appl. Microbiol. Biotechnol. 2009, 84, 11-18. [CrossRef] [PubMed]

105. El-Howeity, M.A.; Asfour, M.M. Response of some varieties of canola plant (Brassica napus L.) cultivated in a newly reclaimed desert to plant growth promoting rhizobacteria and mineral nitrogen fertilizer. Ann. Agric. Sci. 2012, 57, 129-136. [CrossRef]

106. Bertrand, H.; Nalin, R.; Bally, R.; Cleyet-Marel, J.-C. Isolation and identification of the most efficient plant growth-promoting bacteria associated with canola (Brassica napus). Biol. Fertil. Soils 2001, 33, 152-156. [CrossRef]

107. Ntalli, N.; Ferrari, F.; Giannakou, I.O.; Menkissoglu-Spiroudi, U. Synergistic and antagonistic interactions of terpenes against Meloidogyne incognita and the nematicidal activity of essential oils from seven plants indigenous to Greece. Pest. Manag. Sci. 2011, 67, 341-351. [CrossRef] [PubMed]

108. Jiménez-Reyes, M.F.; Carrasco, H.; Olea, A.F.; Silva-Moreno, E. Natural Compounds: A Sustainable Alternative to the Phytopathogens Control. J. Chil. Chem. Soc. 2019, 64, 4459-4465. [CrossRef]

109. Da Silva, F.; Alves, C.; Oliveira Filho, J.; Vieira, T.; Crotti, A.E.; Miranda, M. Chemical constituents of essential oil from Murraya paniculata leaves and its application to in vitro biological control of the fungus Sclerotinia sclerotiorum. Food Sci. Technol. 2019, 39. [CrossRef]

110. Valadares, A.C.F.; Alves, C.C.F.; Alves, J.M.; de Deus, I.P.B.; de Oliveira Fi, J.G.; Dos Santos, T.C.L.; Dias, H.J.; Crotti, A.E.M.; Miranda, M.L.D. Essential oils from Piper aduncum inflorescences and leaves: Chemical composition and antifungal activity against Sclerotinia sclerotiorum. An. Acad. Bras. Cienc. 2018, 90, 2691-2699. [CrossRef]

111. Yang, C.; Yang, C.; Gao, X.; Jiang, Y.; Sun, B.; Gao, F.; Yang, S. Synergy between methylerythritol phosphate pathway and mevalonate pathway for isoprene production in Escherichia coli Synergy between methylerythritol phosphate pathway and mevalonate pathway for isoprene production in Escherichia coli. Metab. Eng. 2016, 37, 79-91. [CrossRef]

112. Syed, S.; Prasad Tollamadugu, N.V.K.V. Chapter 16-Role of Plant Growth-Promoting Microorganisms as a Tool for Environmental Sustainability. In Recent Developments in Applied Microbiology and Biochemistry; Buddolla, V., Ed.; Academic Press: Cambridge, MA, USA, 2019; pp. 209-222. ISBN 978-0-12-816328-3.

113. Dobbelaere, S.; Vanderleyden, J.; Okon, Y. Plant Growth-Promoting Effects of Diazotrophs in the Rhizosphere. CRC Crit. Rev. Plant Sci. 2003, 22, 107-149. [CrossRef]

114. Chen, F.; Han, P.; Liu, P.; Si, N.; Liu, J.; Liu, X. Activity of the novel fungicide SYP-Z048 against plant pathogens. Sci. Rep. 2014, 4, 6473. [CrossRef]

115. Guzmán-Guzmán, P.; Porras-Troncoso, M.D.; Olmedo-Monfil, V.; Herrera-Estrella, A. Trichoderma Species: Versatile Plant Symbionts. Phytopathology 2018, 109, 6-16. [CrossRef] [PubMed]

116. Finkel, O.M.; Castrillo, G.; Herrera Paredes, S.; Salas González, I.; Dangl, J.L. Understanding and exploiting plant beneficial microbes. Curr. Opin. Plant. Biol. 2017, 38, 155-163. [CrossRef] [PubMed]

117. Anthony, J.R.; Anthony, L.C.; Nowroozi, F.; Kwon, G.; Newman, J.D.; Keasling, J.D. Optimization of the mevalonate-based isoprenoid biosynthetic pathway in Escherichia coli for production of the anti-malarial drug precursor amorpha-4,11-diene. Metab. Eng. 2009, 11, 13-19. [CrossRef] [PubMed]

118. Ajikumar, P.K.; Xiao, W.-H.; Tyo, K.E.J.; Wang, Y.; Simeon, F.; Leonard, E.; Mucha, O.; Phon, T.H.; Pfeifer, B.; Stephanopoulos, G. Isoprenoid Pathway Optimization for Taxol Precursor Overproduction in Escherichia coli. Science (80-) 2010, 330, 70-74. [CrossRef]

119. Henke, N.; Wichmann, J.; Baier, T.; Frohwitter, J.; Lauersen, K.; Risse, J.; Peters-Wendisch, P.; Kruse, O.; Wendisch, V. Patchoulol Production with Metabolically Engineered Corynebacterium glutamicum. Genes 2018, 9, 219. [CrossRef]

120. Frohwitter, J.; Heider, S.A.E.; Peters-Wendisch, P.; Beekwilder, J.; Wendisch, V.F. Production of the sesquiterpene (+)-valencene by metabolically engineered Corynebacterium glutamicum. J. Biotechnol. 2014, 191, 205-213. [CrossRef]

121. Chen, H.; Zhu, C.; Zhu, M.; Xiong, J.; Ma, H.; Zhuo, M.; Li, S. High production of valencene in Saccharomyces cerevisiae through metabolic engineering. Microb. Cell Fact. 2019, 18, 195.

122. Westfall, P.J.; Pitera, D.J.; Lenihan, J.R.; Eng, D.; Woolard, F.X.; Regentin, R.; Horning, T.; Tsuruta, H.; Melis, D.J.; Owens, A.; et al. Production of amorphadiene in yeast, and its conversion to dihydroartemisinic acid, precursor to the antimalarial agent artemisinin. Proc. Natl. Acad. Sci. USA 2012, 109, E111-E118.

123. Englund, E.; Shabestary, K.; Hudson, E.P.; Lindberg, P. Systematic overexpression study to find target enzymes enhancing production of terpenes in Synechocystis PCC 6803, using isoprene as a model compound. Metab. Eng. 2018, 49, 164-177. [CrossRef] 
124. Bentley, F.K.; Zurbriggen, A.; Melis, A. Heterologous expression of the mevalonic acid pathway in cyanobacteria enhances endogenous carbon partitioning to isoprene. Mol. Plant. 2014, 7, 71-86. [CrossRef]

125. Krieg, T.; Sydow, A.; Faust, S.; Huth, I.; Holtmann, D. $\mathrm{CO}_{2}$ to Terpenes: Autotrophic and Electroautotrophic $\alpha$-Humulene Production with Cupriavidus necator. Angew. Chem. Int. Ed. 2018, 57, 1879-1882. [CrossRef] [PubMed]

126. Yang, J.; Li, Z.; Guo, L.; Du, J.; Bae, H.-J. Biosynthesis of $\beta$-caryophyllene, a novel terpene-based high-density biofuel precursor, using engineered Escherichia coli. Renew. Energy 2016, 99, 216-223. [CrossRef]

127. Yang, J.; Nie, Q. Engineering Escherichia coli to convert acetic acid to $\beta$-caryophyllene. Microb. Cell Fact. 2016, 15, 74. [CrossRef] [PubMed]

128. Hogenkamp, F.; Hilgers, F.; Knapp, A.; Klaus, O.; Bier, C.; Binder, D.; Jaeger, K.-E.; Drepper, T.; Pietruszka, J. Effect of Photocaged Isopropyl $\beta$-D-1-Thiogalactopyranoside Solubility on Light-Responsiveness of LacI-controlled Expression Systems in Different Bacteria. ChemBioChem 2020. [CrossRef] [PubMed] 